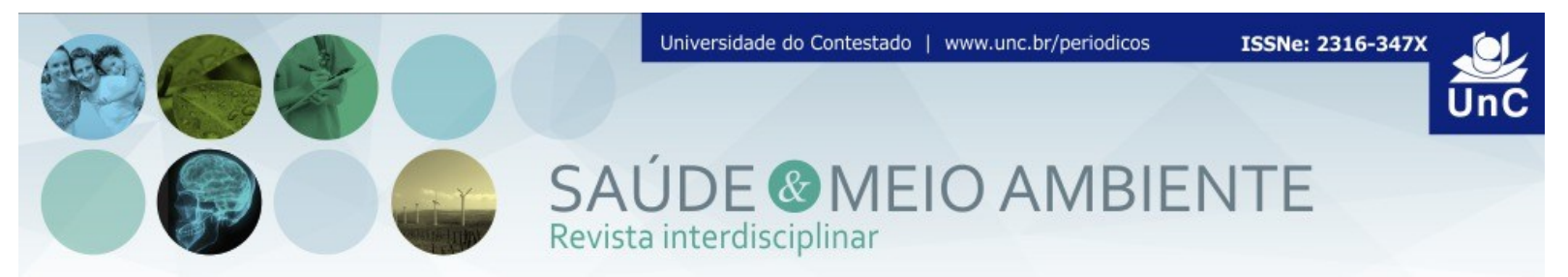

\title{
REUSO DE EMBALAGENS CARTONADAS PARA DESCARTE ADEQUADO DE PILHAS E BATERIAS
}

\author{
Célia Cristina Campanaro $\mathrm{Noe}^{1}$ \\ Beatriz Alves ${ }^{2}$ \\ Ligia Ajaime Azzalis ${ }^{3}$ \\ Virginia Berlanga Campos Junqueira ${ }^{4}$ \\ Rogério Alvarenga ${ }^{5}$ \\ Tatiana Dias de Carvalho ${ }^{6}$ \\ Odair Ramos de Silva ${ }^{7}$ \\ Fernando Luiz Affonso Fonseca ${ }^{8}$
}

RESUMO: Introdução: Pensando em achar soluções simples e práticas para minimizar os impactos que os resíduos sólidos causam a saúde e ao meio ambiente, elaborou-se um recipiente para coleta de pilhas e baterias a partir de embalagens cartonadas. Objetivo: Descrever o uso de embalagens cartonadas como coletoras para descarte adequado de pilhas e baterias após seu esgotamento. Método: Em laboratório multidisciplinar da FMABC, as embalagens cartonadas (Tetra Pak) foram submetidas a testes de resistência, tempo de utilização, quantidade de armazenamento e aspectos químicos. Para verificar o período de utilização das embalagens e observar sua integridade em relação à quantidade de pilhas e baterias, foram realizadas oito inspeções visuais. Para verificar a resistência das caixas em relação a elementos químicos, foram efetuados testes em que as embalagens foram submetidas a soluções eletrolíticas presentes nas pilhas e baterias. Resultados: Durante o acompanhamento por meio das inspeções visuais, foram observadas que as embalagens cartonadas são resistentes quanto aos testes realizados com soluções eletrolíticas. Em termos de resistência e quantidade de armazenamento de pilhas, constatou-se que o período de um ano é válido para uso das caixas como coletoras. Conclusão: as embalagens cartonadas são resistentes

${ }^{1}$ Curso de Gestão em Saúde Ambiental da Faculdade de Medicina do ABC, FMABC, Santo André, Brasil. E-mail: celia.campanaro@terra.com.br.

${ }^{2}$ Laboratório de Análises Clínicas da Faculdade de Medicina do ABC, FMABC, Santo André, Brasil. E-mail: bcaalves@uol.com.br

${ }^{3}$ Instituto de Ciências Ambientais, Químicas e Farmacêuticas, Universidade Federal de São Paulo, Diadema, Brasil. E-mail: lazzalis@uol.com.br

${ }^{4}$ Instituto de Ciências Ambientais, Químicas e Farmacêuticas, Universidade Federal de São Paulo, Diadema, Brasil. E-mail: virginia.junqueira@uol.com.br

${ }^{5}$ Curso de Gestão em Saúde Ambiental da Faculdade de Medicina do ABC, FMABC, Santo André, Brasil. E-mail: ralvarenga@gmail.com

${ }^{6}$ Curso de Gestão em Saúde Ambiental da Faculdade de Medicina do ABC, FMABC, Santo André, Brasil. E-mail: taticarvalho@gmail.com

${ }^{7}$ Curso de Gestão em Saúde Ambiental da Faculdade de Medicina do ABC, FMABC, Santo André, Brasil. E-mail: orsilva@hotmail.com.br

${ }^{8}$ Curso de Gestão em Saúde Ambiental da Faculdade de Medicina do ABC, FMABC, Santo André. Laboratório de Análises Clínicas da Faculdade de Medicina do ABC, FMABC, Santo André, Brasil. Instituto de Ciências Ambientais, Químicas e Farmacêuticas, Universidade Federal de São Paulo, Diadema, Brasil. E-mail: profferfonseca@gmail.com 
e não sofreram alterações químicas, possibilitando seu uso como coletoras para descarte adequado de pilhas e baterias.

Palavras-chave: Gestão de resíduos sólidos. Coleta seletiva. Metais pesados. Pilhas e embalagens cartonadas.

\section{REUSE OF CARTONS AS GATHERERS SUITABLE FOR DISPOSAL OF CELLS AND BATTERIES}

ABSTRACT: Background: Thinking about finding simple solutions and practices to minimize the impact that solid waste cause health and the environment, drew up a container to collect batteries from recyclable materials. Objective: To describe the use of cartons as collector for proper disposal of batteries after their depletion. Method: In a multidisciplinary laboratory FMABC, cartons (tetra Pak) were tested for resistance, time of use, amount of storage and chemical aspects. To check the of use packaging and abserve its integrity in relation to the quantily of batteries, eight visual inspections were performed. To check the resistance of the boxes in relation to chemicals tests were performed in which the packages were subjeted to electrolytic solutions present in batteries. Results: During follow-up inspections were visually observed that the cartons are sturdy as the tests performed with electrolyte solutions. In terms of strength and amount of storage batteries was found that the valid period for use as collecting boxes can be a year should not be higher than this set period and if present the same integrity as to its physical aspects may be usually discarded as waste for recycling. Conclusion: The cartons are sturdy and can be reused as a collector for proper disposal of batteries.

Keywords: Management of solid waste. Heavy metals. Batteries. Pachaging carton and reuse.

\section{INTRODUÇÃO}

O processo de industrialização e urbanização trouxe consigo mudanças de hábitos e padrões de consumo, impondo um período de tempo curto para suas mercadorias. Assim, um grande volume de descarte é gerado, surgindo para a sociedade o desafio de dar destinação adequada a resíduos cuja decomposição demanda séculos (SIQUEIRA; MORAIS, 2009).

A partir daí, surgiu no meio urbano o trabalho de coleta e reciclagem dessas mercadorias, desde que tratados adequadamente (MEDEIROS; MACEDO, 2006). A reciclagem proporciona redução de matérias-primas e energia, aumentando a vida útil de aterros sanitários (CRUZ, 2002).

A disposição final ambientalmente correta e segura dos resíduos sólidos é um dos maiores desafios para a sociedade moderna. O gerenciamento inadequado 
desses resíduos pode resultar em riscos para a qualidade de vida das comunidades, criando, ao mesmo tempo, problemas de saúde pública (GIARETTA et al., 2010; JACOBI; BESEN, 2011). Um exemplo disso são as pilhas e baterias de uso doméstico que, apesar de pequenas e de aparência inofensiva, apresentam um grande perigo quando descartadas incorretamente (GIARETTA et al., 2010; CARIBÉ et al., 2011; INMETRO, 2012).

As pilhas e baterias levam de 100 a 500 anos para se decomporem. Os efeitos da exposição de pilha são pequenos enquanto os metais e outras substâncias químicas estiverem blindados dentro da embalagem da pilha. Uma exposição potencial pode ocorrer em caso de vazamento ou ruptura de sua blindagem (AGOURAKIS et al., 2006).

Devido às propriedades químicas (características de corrosividade, reatividade e toxicidade), o descarte de pilhas e baterias no lixo urbano (lixões) ou in natura gera problemas nas estações de tratamento de lixo, poluem os solos e lençóis freáticos, afetando a flora e a fauna das regiões circunvizinhas e o homem pela cadeia alimentar (CARIBÉ et al., 2011; AGOURAKIS et al., 2006; GOMES; MELO, 2006). Na composição dessas pilhas e baterias, também são encontrados metais pesados tais como cádmio, chumbo, mercúrio e outros que são elementos bioacumulativos, ou seja, não são sintetizados nem destruídos pelo homem, motivo pelo qual são tão prejudiciais à saúde humana e ao meio ambiente (AGOURAKIS et al., 2006; GOMES; MELO, 2006).

Uma maneira consciente de armazenar adequadamente esses resíduos sólidos em casa, no escritório, mercado ou comércio em geral, até serem levados a postos de coleta onde posteriormente são transportados para descarte adequado seria sua acomodação em um recipiente em que, caso as pilhas venham a vazar, não prejudiquem a saúde humana.

Outro resíduo que se destaca são as embalagens cartonadas (Tetra Pak) que apresentam em sua composição três materiais: papel, polietileno e alumínio, nas proporções, em peso, de $75 \%, 20 \%$ e $5 \%$, respectivamente, tornando-as muito resistentes e eficientes. Estas embalagens podem ser armazenadas por meses sem refrigeração ou conservantes, com maior nível de segurança ao seu conteúdo (CARASCHI et al., 2009; NEVES, 2012).

Pressupondo que será um bem para a sociedade e devido aos constantes apelos sobre os cuidados com o meio ambiente e as necessidades de se constituir um mundo mais sustentável para as próximas gerações (BRASIL, 2010), surgiram as questões: por que não desenvolver um recipiente resistente para coletas de pilhas e baterias? Por que não reutilizar um recipiente já existente, evitando assim que essas embalagens acabem em lixões assim como as pilhas e baterias?

Pensando em achar soluções simples e práticas para minimizar os impactos que os resíduos sólidos causam ao meio ambiente, elaborou-se um recipiente para coleta de pilhas e baterias a partir de materiais recicláveis.

O objetivo deste trabalho é descrever o uso de embalagens cartonadas (Tetra Pak) como coletoras para descarte adequado de pilhas e baterias. 


\section{MÉTODO}

O presente estudo desenvolveu, no laboratório Multidisciplinar da Faculdade de Medicina do ABC, Santo André-SP, um método para descrever o uso das embalagens cartonadas (Tetra Pak) para armazenamento de pilhas e baterias após seu esgotamento, em relação à resistência das caixas, ao tempo de utilização, à quantidade de armazenamento e aos elementos químicos, num período de um ano.

As embalagens cartonadas foram lavadas e secas, e mantidas a uma temperatura entre $18^{\circ} \mathrm{C}$ e $33^{\circ} \mathrm{C}$ e ao abrigo da chuva.

Para verificar o período de utilização das embalagens e observar sua integridade em relação à quantidade de pilhas e baterias, foram realizadas oito inspeções visuais por um mesmo avaliador, nos seguintes intervalos de tempo: 1, 7, $14,21,30,90,180$ e 360 dias.

A fim de observar e verificar a resistência da embalagem cartonada, foram introduzidas 80 pilhas $A A$, quantidade suficiente para enchê-la.

Para verificar a resistência das caixas em relação a elementos químicos, caso as pilhas vazassem, foram efetuados testes em que as embalagens foram submetidas aos componentes químicos cloreto de amônia $\left(\mathrm{NH}_{4} \mathrm{Cl}\right)$ e hidróxido de potássio $(\mathrm{KOH})$, agentes químicos encontrados em pilhas alcalinas. As inspeções visuais foram realizadas quatro vezes, com intervalo de tempo de uma semana entre elas, num total de 30 dias.

\section{AVALIAÇÃO DO TEMPO E RESISTÊNCIA}

Em cinco caixas, foram distribuídas uma, cinco, dez, quinze e vinte pilha, respectivamente, para avaliação em relação ao tempo de armazenamento. A amostragem foi realizada em duplicidade, como mostra a figura 1. Uma amostragem continhas apenas pilhas da marca (DURACELL $®$ ) (Figura 1a), enquanto a outra, pilhas de diferentes marcas (Figura 1b). 
Figura 1 - Avaliação do recipiente quanto ao tempo e quantidade de pilhas. 1a: pilhas da marca DURACELL®. 1b: pilhas de diferentes marcas.

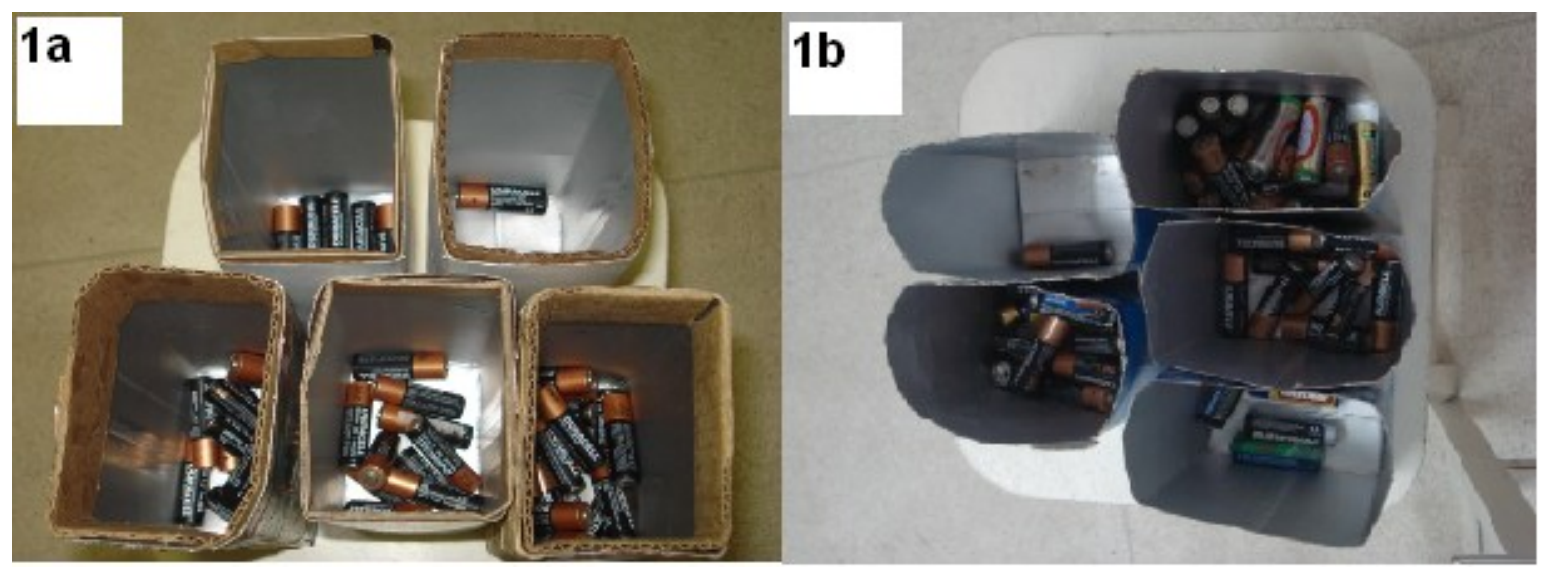

\section{ASPECTO QUÍMICO}

Quanto aos aspectos químicos, foram realizadas amostragens com soluções hidróxido de potássio $(\mathrm{KOH})$ e cloreto de amônia $\left(\mathrm{NH}_{4} \mathrm{Cl}\right)$, agentes químicos encontrados em varias marcas de pilhas alcalinas.

Esta análise foi realizada recortando-se duas caixas cartonadas ao meio. $\mathrm{Na}$ parte inferior da caixa, foram introduzidos $60 \mathrm{~mL}$ da solução de $\mathrm{KOH}$ com concentração de 1,0 mol/L; na outra parte da embalagem, foram adicionados $60 \mathrm{~mL}$ da solução $\mathrm{NH}_{4} \mathrm{Cl}$ com concentração de $1,0 \mathrm{~mol} / \mathrm{L}$. A parte superior de cada caixa foi utilizada como tampa, apenas para proteção do conteúdo, como mostra a figura 2.

Figura 2 - Avaliação do recipiente quanto aos aspectos químicos.

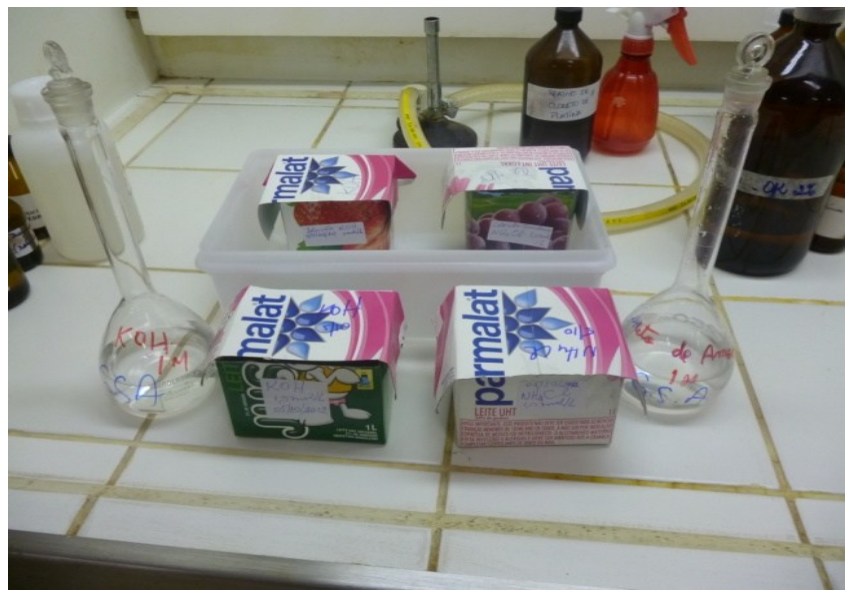

A amostragem do aspecto químico também foi realizada em duplicidade; na primeira amostragem, as embalagens cartonadas eram de suco e na segunda 
amostragem, as caixas eram de leite. Em ambos os casos, as embalagens cartonadas são Tetra Pak (Figura 2).

\section{RESULTADOS E DISCUSSÃO}

Durante o período de acompanhamento visual das oito inspeções realizadas no laboratório Multidisciplinar da Faculdade de Medicina do $A B C$, não houve alterações das embalagens cartonadas em nenhuma das duas amostragens. As caixas contendo pilhas com princípio de corrosão permaneceram intactas, apresentando apenas pequenas ferrugens, conforme apresentado na Figura 3.

Figura 3 - Pilhas com princípio de corrosão.

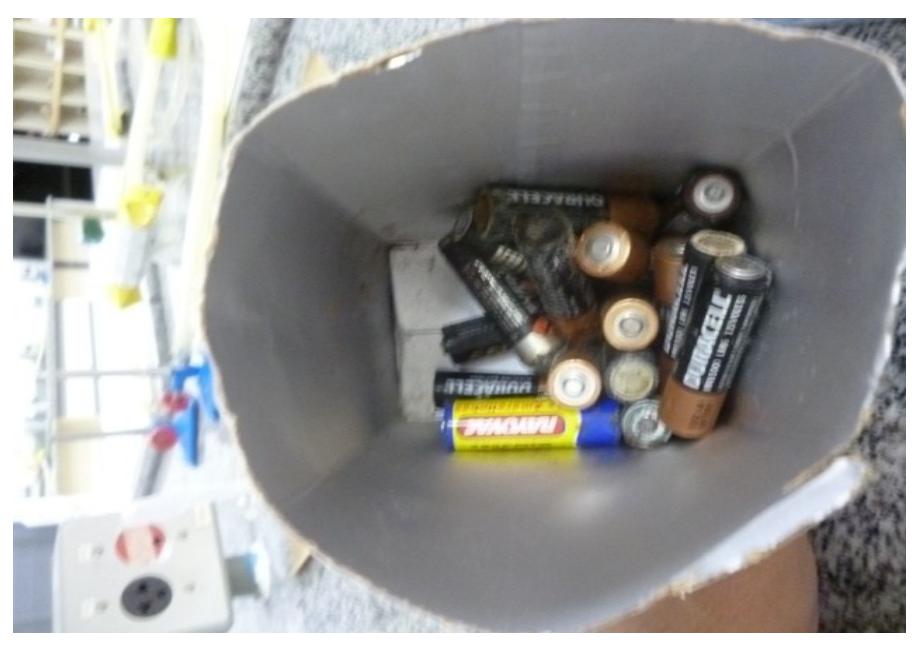

Conforme apresentado na Tabela 1, as cinco embalagens cartonadas contendo uma, cinco, dez, quinze e vinte pilhas, respectivamente, não apresentaram alteração em relação a sua integridade, indicando que o período de um ano é um período válido para se estabelecer o tempo de utilização das caixas como coletoras de pilhas e baterias exauridas.

No recipiente de n. 6 , que continha 80 pilhas, a aparência da caixa permaneceu inalterada; no período de um ano, a caixa não sofreu manuseio, ou seja, não foi mudada de lugar (Tabela 1). 
Tabela 1 - Avaliação do recipiente quanto ao tempo e quantidade de pilhas.

\begin{tabular}{|c|c|c|c|c|c|c|c|c|c|}
\hline Recipiente & Quantidade & $\begin{array}{l}1^{\text {a }} \\
\text { Obs. }\end{array}$ & $\begin{array}{l}2^{a} \\
\text { Obs. }\end{array}$ & $\begin{array}{l}3^{\mathrm{a}} \\
\text { Obs. }\end{array}$ & $\begin{array}{l}4^{\mathrm{a}} \\
\text { Obs. }\end{array}$ & $\begin{array}{l}5^{\text {a }} \\
\text { Obs. }\end{array}$ & $\begin{array}{l}6^{\mathrm{a}} \\
\text { Obs. }\end{array}$ & $\begin{array}{l}7^{\mathrm{a}} \\
\text { Obs. }\end{array}$ & $8^{\text {a }}$ Obs. \\
\hline n. 1 & 1 pilha & S.A. & S.A. & S.A. & S.A. & S.A. & S.A. & S.A. & $\begin{array}{l}\text { Pequenos } \\
\text { pontos de } \\
\text { ferrugens }\end{array}$ \\
\hline n. 2 & 5 pilhas & S.A. & S.A. & S.A. & S.A. & S.A. & S.A. & S.A. & S.A. \\
\hline n. 3 & 10 pilhas & S.A. & S.A. & S.A. & S.A. & S.A. & S.A. & S.A. & S.A. \\
\hline n. 4 & 15 pilhas & S.A. & S.A. & S.A. & S.A. & S.A. & S.A. & S.A. & $\begin{array}{l}\text { Pequenos } \\
\text { pontos de } \\
\text { ferrugens }\end{array}$ \\
\hline n. 5 & 20 pilhas & S.A. & S.A. & S.A. & S.A. & S.A. & S.A. & S.A. & $\begin{array}{l}\text { Pequenos } \\
\text { pontos de } \\
\text { ferrugens }\end{array}$ \\
\hline n. 6 & 80 pilhas & S.A. & S.A. & S.A. & S.A. & S.A. & S.A. & S.A. & S.A. \\
\hline
\end{tabular}

S.A. - sem alterações

Com relação aos aspectos químicos analisados com soluções eletrolíticas $\mathrm{KOH}(1,0 \mathrm{~mol} / \mathrm{L})$ e $\mathrm{NH}_{4} \mathrm{Cl}(1,0 \mathrm{~mol} / \mathrm{L})$, após as quatro observações efetuadas, não houve alterações das embalagens cartonadas em nenhuma das amostragens.

A resolução CONAMA 401/2008 estabelece os limites máximos de chumbo, cádmio e mercúrio para pilhas e baterias comercializadas no território nacional e os critérios e padrões para o seu gerenciamento ambientalmente adequado (BRASIL, 2008). Apesar disso, a simples existência de uma lei, independentemente de seu conteúdo, não é suficiente para que a mesma seja conhecida e muito menos cumprida (REIDLER; GUNTHER, 2003).

A legislação brasileira proíbe formas inadequadas de disposição ou destinação final de pilhas e baterias usadas, de quaisquer tipos ou características. Entretanto, essa legislação não dispõe sobre outros tipos, que contenham em sua composição outros metais ou substâncias tão prejudiciais à saúde e ao ambiente quanto às referidas no texto das Resoluções em vigência; nem todos os tipos de pilhas e baterias apresentam o mesmo grau de periculosidade (REIDLER; GUNTHER, 2003). Ao contrário, apesar de pequenas e de aparência inofensiva, as pilhas e baterias apresentam um grande perigo quando descartadas incorretamente (GIARETTA et al., 2010; CARIBÉ et al., 2011).

A bateria é uma fonte portátil de energia, resultante das reações químicas que ocorrem em seu interior. A pilha elétrica é composta de três itens básicos: um ânodo, um cátodo e um eletrólito. O ânodo é o eletrodo negativo (pólo negativo), o cátodo o eletrodo positivo (pólo positivo) e o eletrólito o condutor iônico que envolve os eletrodos de uma pilha, ou seja, a solução condutiva entre os dois eletrodos (CARIBÉ et al., 2011; INMETRO, 2012). Ela é composta por elementos químicos como dióxido de manganês $\left(\mathrm{MnO}_{2}\right)$, cloreto de zinco $\left(\mathrm{ZnCl}_{2}\right)$, cloreto de amônia (NH4Cl) e hidróxido de sódio $(\mathrm{NaOH})$ ou hidróxido de potássio $(\mathrm{KOH})$ (AGOURAKIS et al., 2006; REIDLER; GUNTHER, 2003). 
Do ponto de vista químico, mesmo os metais que representam menores riscos em sua forma elementar, quando descartados sem controle junto com o resíduo sólido comum podem se transformar em substâncias extremamente perigosas e tóxicas à saúde e ao ambiente, pela possibilidade de reação, interação ou sinergismo com outras substâncias presentes no resíduo sólido urbano (REIDLER; GUNTHER, 2003).

Os metais estão presentes em todas as formas de vida e a manifestação de efeitos tóxicos está associada à dose e à forma química. Eles são importantes para o crescimento de bactérias e de todos os tipos de organismo, até mesmo para o ser humano. Ao distribuírem-se por todo o organismo, podem alterar os processos bioquímicos, organelas e membranas celulares afetando vários órgãos (MORAES; JORDÃO, 2002; CELERE et al., 2007). Isso acontece quando as doses internas máximas estão acima das admissíveis ou toleráveis (MOREIRA; MOREIRA, 2004).

O gerenciamento inadequado desses resíduos pode resultar em riscos para a qualidade de vida das comunidades, criando, ao mesmo tempo, problemas de saúde pública (GIARETTA et al., 2010; JACOBI; BESEN, 2011). O câncer, anúria, anemia, disfunções digestivas, cerebrais, neurológicas, renais e hepáticas, nefropatia, gotas saturnínicas, úlceras na pele, paralisia dos membros, encefalopatia aguda e crônica e mutações genéticas estão entre os males provocados pela intoxicação com metais pesados (INMETRO, 2012; BRASIL, 2008; REIDLER; GUNTHER, 2003; PINHEIRO et al., 2009). O chumbo atinge o sistema nervoso e medula óssea e os rins; o cádmio causa problemas gastrointestinais e respiratórios e o mercúrio se concentra em varias parte do corpo, como pele, cabelo, tireóide, pulmões, pâncreas, fígado, rins e aparelhos reprodutivos (REIDLER; GUNTHER, 2003).

A Lei 12.305 da Política Nacional de Resíduos Sólidos descreve a responsabilidade compartilhada como um conjunto de soluções para minimizar o volume de resíduos sólidos e rejeitos, reduzindo os impactos causados à saúde humana e a qualidade ambiental. Sendo assim, a reciclagem começa dentro de casa com atitudes simples, firmando que a reutilização dos resíduos sólidos também são práticas descritas em forma de lei, vindo de encontro ao objetivo deste trabalho em achar soluções simples e exequíveis para tentar minimizar os impactos que os resíduos sólidos causam ao meio ambiente, ao propor um recipiente para coleta de pilhas e baterias a partir de materiais recicláveis.

As embalagens cartonadas, que devido a sua composição (papel, polietileno e alumínio) são resistentes (CARASCHI et al., 2009; NEVES, 2012), podem ser reutilizadas como coletoras de pilhas.

A embalagem cartonada tem provocado grande impacto ambiental nas últimas décadas, pela dificuldade de separar e reciclar os elementos que compõem o produto (PEREIRA et al., 2008). A Tetra Pak que investe em reciclagem em função de um projeto de responsabilidade ambiental. Empenhada em incentivar o aumento da coleta seletiva, desenvolver novas tecnologias de reciclagem e incentivar as recicladoras, a empresa estima que $10 \%$ de suas embalagens já são reprocessadas (CRUZ, 2002). 
As embalagens cartonadas e plásticas pós-consumo podem ser também fontes de matéria-prima para a produção de materiais alternativos. Porém, os resultados obtidos a partir das propriedades físicas e mecânicas dos painéis confeccionados a base de embalagem cartonada apresentaram resultados insatisfatórios, principalmente com relação à absorção de água e ao inchamento em espessura (CARASCHI et al., 2009).

O local para armazenamento das pilhas, baterias e lâmpadas usadas deverá ser coberto e bem ventilado, protegido do sol e das chuvas, a fim de que o material seja mantido seco (PINHEIRO et al., 2009). Motivo pelo qual nossas caixas foram mantidas em locais e condições adequadas para não prejudicar as embalagens cartonadas e para que seu conteúdo não sofresse alterações químicas.

Para pilhas e baterias, o recipiente deve ser resistente, devido ao peso do material que será ali depositado. As caixas devem ser de materiais não condutores de eletricidade. Adverte-se para a não utilização de tambores ou contêineres metálicos, de modo a evitar a formação de curtos circuitos e vazamentos precoces da pasta eletrolítica, o que tornará a manipulação do material mais difícil (PINHEIRO et al., 2009). Por isso nossa opção por usar as caixas cartonadas, visto que são compostas por papel, alumínio e polietileno, sendo que este as reveste nas duas últimas camadas, evitando assim que seu conteúdo entre em contato com 0 alumínio.

No que diz respeito às observações visuais (Tabela 1), ao se depositar pilhas e baterias nas embalagens cartonadas, elas não entraram em contato com o alumínio devido ao seu revestimento, não sofrendo curtos circuitos, justificando novamente seu uso como coletoras para pilhas e baterias.

A lei 8078/90 Instituto Brasileiro de Defesa do Consumidor estabelece que pela garantia dos produtos e serviço com padrões adequados de qualidade, segurança, durabilidade e desempenho, em se tratando de produto industrial, ao fabricante cabe prestar estas informações por meio de impressos apropriados que devam acompanhar o produto (IDEC, 1990), ou seja, os rótulos nos produtos são necessários para estabelecer a confiabilidade do produto, importando informações relevantes ao consumidor.

Em termos de durabilidade do uso das caixas cartonadas, o presente estudo estabelece que o período de um ano seja apropriado para que elas sejam utilizadas como coletoras de pilhas e baterias, uma vez que as inspeções realizadas ao longo deste período não identificaram alterações na integridade física das embalagens (Tabela 1).

Nos casos em que a integridade física da embalagem é mantida, ela pode ser descartada corretamente como resíduo para reciclagem, prolongando assim por mais um ano seu ciclo de vida. Isso porque os bens de pós-consumo são os produtos que já estão no final da vida útil, que pode ser prolongada se outras pessoas encontrarem ainda utilidade no produto, mantendo-o em uso por mais tempo. Quando chega ao final da vida útil o produto pode ser reciclado ou depositado em aterros, o que causa impacto ao meio ambiente. Isso significa que há 
três possibilidades no pós-consumo: o reuso, a reciclagem e a destinação final em aterros (PEREIRA et al., 2008). Todo resíduo sólido que possa ser reutilizado ou reciclado contribui para minimizar a quantidade destes materiais em aterros, prolongando assim a vida útil tanto do resíduo quanto do aterro (CRUZ, 2002).

Os Resíduos Sólidos são considerado hoje como um dos grandes problemas da sociedade e do poder público, devido não ter um gerenciamento adequado que vai desde produção, coleta e disposição final do mesmo. Com o gerenciamento inadequado desses resíduos compromete-se cada vez mais a saúde da população, bem como a degradação dos recursos naturais, assim como os solos e lençóis freáticos (SANTANA, 2010). Torna-se, portanto, imprescindível a realização de mais pesquisas sobre essa temática, que visem à criação de alternativas de baixo custo, permitindo não só o reuso de certos resíduos, como também o armazenamento adequado de outros, até serem levados a postos de coleta onde posteriormente são transportados para descarte adequado.

\section{CONCLUSÃO}

Segundo as observações e análises realizadas no período de um ano, conclui-se que as embalagens cartonadas são resistentes e não sofreram alterações químicas, possibilitando seu uso como coletoras para descarte adequado de pilhas e baterias.

\section{REFERÊNCIAS}

AGOURAKIS, D.C.; CAMARGO, I.M.C.; COTRIM, M.B.; FLUES, M. Componentes de zinco e manganês de pilhas alcalinas em uma coluna de solo. Química Nova, São Paulo, v. 29, n. 5, p. 960-964, 2006.

BRASIL. Ministério do Meio Ambiente. Resolução CONAMA n 401, de 04 de novembro de 2008. Estabelece os limites máximos de chumbo, cádmio e mercúrio para pilhas e baterias comercializadas no território nacional e os critérios e padrões para o seu gerenciamento ambientalmente adequado, e dá outras providencias. Diário Oficial da União, Brasília. DF. 05 nov. 2008.

. Lei Federal $n^{\circ}$ 12.305/2010, de 02 de agosto de 2010. Institui a Política Nacional de Resíduos Sólidos altera a Lei n 9.605, de 12 de fevereiro de 1998 e da outras providencias. Diário Oficial da União, Brasília. DF. 02 ago. 2010.

CARASCHI, J.C.; LEÃO, A.L.; CHAMMA, P.V.C. Avaliação de painéis produzidos a partir de resíduos sólidos para aplicação na arquitetura. Polímeros: Ciência e Tecnologia, v.19, n.1, p. 47-53. 2009. 
CARIBÉ, J.A.Z. et al. Ministério de Desenvolvimento, Indústria e Comercio Exterior. Instituto Nacional de metrologia, qualidade e tecnologia - InMetro. Programa de análise de produtos: Relatório sobre análise em pilhas alcalinas e zincomanganês, Rio de Janeiro, 2011.

CELERE, M.S. et al. Metais presentes no chorume coletado no aterro sanitário de Ribeirão Preto, São Paulo, Brasil, e sua relevância para a Saúde pública. Cadernos de Saúde Pública, v.23, n.4, p. 939-947. 2007.

CRUZ, A.L.M. A reciclagem dos resíduos sólidos urbanos: um estudo de caso. Dissertação (Mestrado em Engenharia de Produção), Florianópolis, 2002. p. 155. Pós-Graduação em Engenharia de Produção, Universidade Federal de Santa Catarina.

EMBALAGENS CARTONADAS DA TETRA PAK. Disponível em:

<http://www.tetrapak.com.br/negocios/embalagens/familias.asp> Acesso em: 23 ago. 2012.

GOMES, A.C.L.; MELO, S.R. Pilhas e efeitos nocivos. Arquivos do Mudi, v. 10, n. 3, p.10-5. 2006.

GUNTHER WMR. Hábitos relacionados do descarte pós-consumo de aparelhos e baterias de telefones celulares em uma comunidade acadêmica. Saúde Sociedade, v. 19, n. 3, p. 674-684, 2010.

IDEC Instituto Brasileiro de Defesa do Consumidor, 1990. Disponível em: <http://www.planalto.gov.br/ccivil_03/leis/L8078compilado.htm>. Acesso em: 22 out. 2012.

InMetro. Instituto de Metrologia, qualidade e tecnologia. Pilhas alcalinas e Zinco. Disponível em: <http://www.inmetro.gov.br/consumidor/produtos/pilha.asp>Acesso em: 22 out. 2012.

JACOBI, P.R.; BESEN, G.R. Gestão de resíduos sólidos em São Paulo: desafios da sustentabilidade. Estudos Avançados, v. 25, n. 71, p. 135-158. 2011.

MEDEIROS, L.F.R; MACEDO, K.B. Catador de material reciclável: uma profissão para além da sobrevivência? Psicologia \& Sociedade, v. 18, n. 2, p. 62-71. 2006.

MORAES, D.S. L.; JORDÃO, B.Q. Degradação de recursos hídricos e seus efeitos sobre a saúde humana. Revista de Saúde Pública, v. 36, n. 3, p. 370-4. 2002.

MOREIRA, F.R.; MOREIRA, J.C. A importância da analise de especiação do chumbo em plasma para avaliação dos riscos à saúde. Quimica Nova, v. 27, n. 2, p. 251-260. 2004.

NEVES FL. Novos desenvolvimentos para reciclagem de embalagens longa vida. Disponível em: <http://afcal.pt/destinoFinal/NovosDesenvolvimentos Reciclagem.pdf>. Acesso em: 05 set. 2012. 
PEREIRA, R.D.A.; PAVANELLI, G.; SOUZA, M.T.S. Um Estudo dos canais reversos em uma empresa de embalagens cartonadas. In: ENCONTRO NACIONAL DE ENGENHARIA DE PRODUÇÃO: a integração de cadeias produtivas com a abordagem da manufatura sustentável; XXVIII. Rio de Janeiro, 2008.

PINHEIRO, E.L.; MONTEIRO, M.A.; FRANCO, R.G.F. Plano de gerenciamento integrado de resíduos: pilhas, baterias e lâmpadas (PGIRPBL). Belo Horizonte, 2009.

REIDLER, N.M.V.L.; GUNTHER, W.M.R. Impactos ambientais e sanitários causados por descarte inadequado de pilhas e baterias usadas. Revista de Limpeza Pública, v. 60 , p. $21-26.2003$.

SANTANA, M.N.R. Plano de gerenciamento e gestão ambiental de resíduos sólidos urbanos no bairro da Vila Pedroso no município de Goiânia. In: CONGRESSO BRASILEIRO DE GESTÃO AMBIENTAL; 1. Bauru, São Paulo, 2010.

SIQUEIRA, M.M.; MORAIS, M.S. Saúde Coletiva, resíduos sólidos urbanos e os catadores de lixo. Ciência e Saúde coletiva, v. 14, n. 6, p. 2115-2122. 2009.

Artigo recebido em: 18/03/2015

Artigo aprovado em: 14/03/2016 